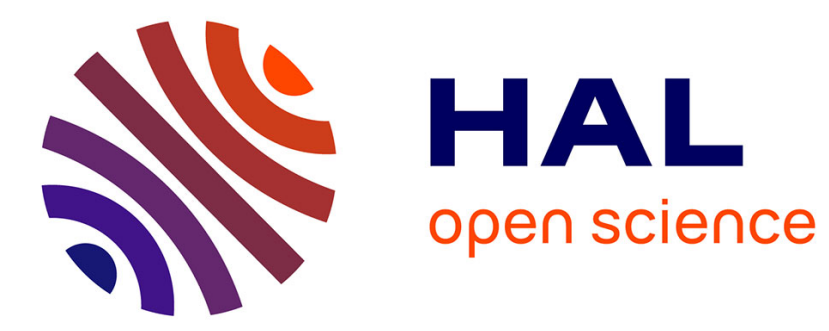

\title{
Titanium alloys. Advances in alloys, processes, products and applications
}

\author{
P. Blenkinsop
}

\section{To cite this version:}

P. Blenkinsop. Titanium alloys. Advances in alloys, processes, products and applications. Journal de Physique IV Proceedings, 1993, 03 (C7), pp.C7-161-C7-169. 10.1051/jp4:1993726 . jpa-00251899

\section{HAL Id: jpa-00251899 https://hal.science/jpa-00251899}

Submitted on 1 Jan 1993

HAL is a multi-disciplinary open access archive for the deposit and dissemination of scientific research documents, whether they are published or not. The documents may come from teaching and research institutions in France or abroad, or from public or private research centers.
L'archive ouverte pluridisciplinaire HAL, est destinée au dépôt et à la diffusion de documents scientifiques de niveau recherche, publiés ou non, émanant des établissements d'enseignement et de recherche français ou étrangers, des laboratoires publics ou privés. 


\title{
Titanium alloys. Advances in alloys, processes, products and applications
}

\author{
P.A. BLENKINSOP
}

Interdisciplinary Research Centre in Materials, For High Performance Applications, The University of Birmingham, Birmingham B15 2TT, U.K.

\begin{abstract}
The last few years have been a period of consolidation of existing alloys and processes. While the aerospace industry remains the principal driving force for alloy development, the paper illustrates examples of new markets being established in 'older' alloys, by a combination of product/process development and a re-examination of engineering design parameters.
\end{abstract}

Considerable attention is still being directed towards the titanium aluminide systems, but other more conventional alloy developments are underway aimed at specific engineering and process requirements, both in the aerospace and non-aerospace sectors. Both the advanced high temperature and conventional alloy developments are considered, before the paper goes on to assess the potential of new processes and products, like spray-forming, metal matrix composites and shaped-plate rolling.

\section{INTRODUCTION}

While new alloys have been developed over the last few years, the existing world economic climate has prompted a re-examination of existing alloys against potential new markets. This decade will see the 50th anniversary of the onset of titanium alloy development. Over most of that period the driving force behind the alloys has been the demands of the aerospace industry. The 1960's and '70's saw considerable strides in alloy development aimed at higher temperatures and strengths. Many of the alloys developed in that period failed to make a technical and commercial impact, not because they were metallurgical failures, but because the aerospace programmes, for which they were developed, were terminated for either political or commercial reasons. One example is the RMI alloy Ti-5-6-2-1S, which was effectively lost when the US cancelled the development of the SST aircraft in the late 1960's and there are many more examples in both to USA and Europe ${ }^{(1)}$.

A combination of the need to establish new markets, a relaxation of the engineering design constraints (i.e. a better understanding of the relationship of mechanical properties in terms of component lifing), and process developments, have all prompted a re-examination of the older alloys. This paper will attempt to address the developments in the older and recently introduced alloys, before considering present alloy research, and process and products developments.

\section{EXISTING ‘OLDER’ ALLOYS}

The titanium alloy developers have achieved significant strides over the last 40 years. A measure of this achievement is illustrated in Figure 1, which shows the progress made in terms of increased creep resistance. Strengths have risen from $300-400 \mathrm{MPa}$ to over $1500 \mathrm{MPa}$, while temperature capabilities have increased from a modest $200^{\circ} \mathrm{C}$ to over $600^{\circ} \mathrm{C}$.

The need to establish new markets, allied to process/product developments, has resulted in the reexamination of older alloys. It is significant, that many of the alloys that were originally produced in billet and bar for forged components, such as discs, blades and struts, have seen extensions of their potential applications through product developments in plate, sheet and castings. Table $I$ lists the alloys which have attracted renewed interest and have either seen extended applications, or in some instances, are likely to secure major use in aerospace for the first time. 


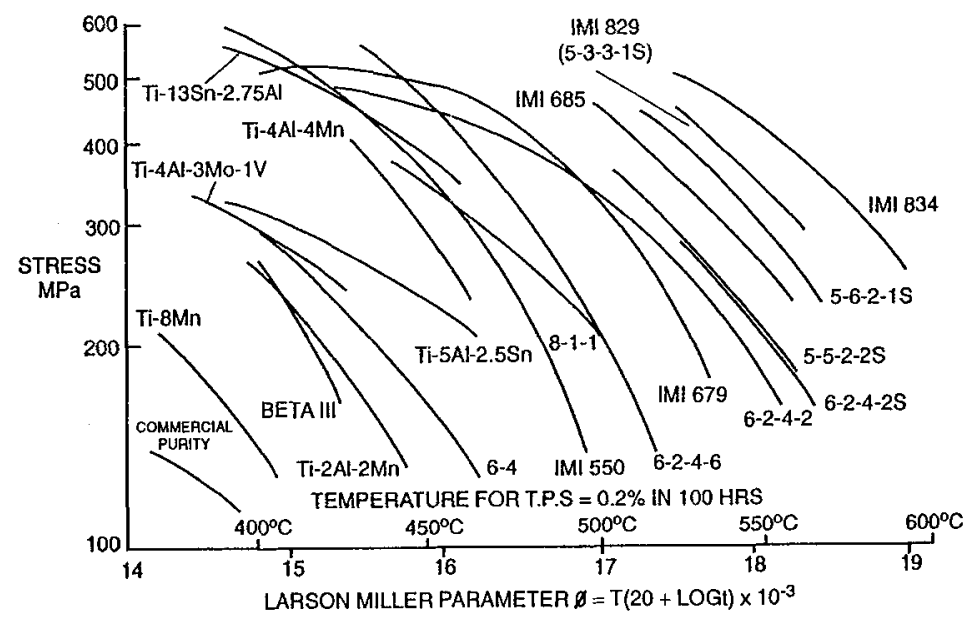

Figure 1 Creep of Titanium alloys.

Table I. Existing Alloys Attracting New Applications

Alloy
Ti-6-22-22
Ti-10-2-3
Ti-15-3-3
Beta CTM
IMI 550

\section{Composition (wt\%)}

It is significant that the alloys have high strength, rather than high temperature capabilities.

Ti-6-22-22 is an alloy that was first publicised in 1972. The alloy shows a good combination of strength and fracture toughness, with room temperature strengths of typically $1200 \mathrm{MPa}$ and fracture toughness in the range 50 to $60 \mathrm{MPa} \sqrt{\mathrm{m}}$. It has now been specified for the two-thirds of the titanium airframe structure for the F-22 Advanced Tactical Fighter. The largest usage is in thick plate and forgings, where the alloy's attractive strength/toughness properties give it a design advantage over Ti-6-4 (2).

Meta-stable beta titanium alloys Ti-10-2-3, Ti-15-3-3 and Beta $\mathrm{C}^{\mathrm{TM}}$ were all developed ten to twenty years ago. While over the years the alloys have found limited applications, it is only recently that significant applications have been identified.

Like all meta-stable beta titanium alloys they can be heat treated to give high strength in combination with high fracture toughness. Ti-10-2-3 was originally developed as a forging alloy, aimed at replacing steel components in airframes, while Ti-15-3-3 was designed as a cold rollable strip alloy. However, the developments in near-to-net shape extrusions and castings have allowed applications to be identified for both alloys in the airframe of the Boeing 777.

Ti-10-2-3 will be used as forged components in the landing gear and net-shape extrusions for seat track crowns, while Ti-15-3-3 high strength castings ( $-1140 \mathrm{MPa}$ UTS) have been specified for landing gear components.

Although Beta $C^{\mathrm{TM}}$ has attracted the attention of the airframe manufacturers, particularly as castings and fasteners, the alloy's major applications, because of its combination of high strength and good corrosion resistance, have been in industrial components. The alloy is being considered for use in sour gas and geothermal wells. 
The final alloy in Table I, IMI 550, is the oldest, being developed in the UK in the late 1950's. It is different from the other alloys in the sense that, since its introduction, it has always found applications in the European aerospace industry. Over 4000 tonnes have been produced in the last 10 years, as components for both aero-engines and airframes. It was originally developed as a medium/high strength creep resistant alloy for the Rolls Royce Pegasus and Olympus engines, which power the Harrier (AV8B) and Concorde, respectively. Since its introduction into engines as discs, more recent applications have been centred on airframe components in both European military and civil aircraft e.g. Jaguar, Tornado and Airbus.

From an alloy development view-point IMI 550 is significant in that it was the first commercial alloy to exploit the benefits of silicon in terms of creep strength and grain refinement. The significant grain refinement, as compared to Ti-6-4, is seen in both the microstructure and macrostruture of IMI 550. The introduction of extrusions, castings and thin SPF quality sheet and plate have all increased the potential applications for MI550; all products have maintained the alloy's significant grain size and tensile, fatigue and creep strength advantages over Ti-6-4. In SPF quality sheet the typical grain size of IMI 550 is 2-3 $\mu \mathrm{m}$ compared to $4-8 \mu \mathrm{m}$ in Ti-6-4.

\section{HIGH TEMPERATURE ALLOYS}

\section{a) Conventional Alloys}

Over the last few years the alloys that have attracted the most attention have been those targetted towards high temperature aero-engine applications. The area splits into two distinct groups. The immediate and medium-term requirements, which are addressed by conventional alloys like

IMI 834 and $\mathrm{Ti}-1100$, and the longer-term aspirations, which are principally concerned with intermetallic systems based on titanium aluminides.

In first considering the conventional alloys, both IMI 834 ( Ti-5.8Al-4Sn-3.5Zr-0.7Nb-0.5Mo-0.35Si$0.06 \mathrm{C}$ ) and $\mathrm{Ti} 1100$ ( Ti-6Al-2.75Sn-4Zr-0.4Mo-0.45Si) have been well-documented in the literature $(3,4)$, where extensive property data is detailed. It is not the intention of this paper to table any comparative mechanical property data, however, it is appropriate to consider the philosophy behind the alloys.

The significant difference between the alloys is that IMI 834 is processed as an $\alpha+\beta$ alloy, the heat treatment being specifically designed to produce a lean primary $\alpha+\operatorname{transformed} \beta$ microstructure. The structure of Ti-1100 is derived, either from $\beta$ forging, or from a full $\beta$ heat treatment, thereby producing a fully transformed acicular $\alpha$ microstructure in the final product. Structures of this type are known to maximise creep at the expense of fatigue strength. Similarly processed alloys, such as IMI 685 and IMI 829 , have been used successfully for over 20 years in Europe in the compressor stages of both military and civil aero-engines.

The $\alpha+\beta$ microstructure associated with IMI 834 is aimed at optimising the balance of properties, particularly those of fatigue and creep strengths. The use of an $\alpha+\beta$ heat treatment to produce a low level of primary $\alpha$, typically 7 to $15 \%$, is only possible because of the alloy's composition, in particular the presence of carbon, and the advances that have occurred over the last decade in production melting, forging and heat treatment technologies and practices. Twenty years ago an alloy of this type would not have been possible as a production reality. Figure 2 shows the significant difference in the shape of the $\beta$ approach curve, between IMI 834 and other titanium alloys. It is the shallow form of the curve, resulting from the presence of carbon in the alloy, which allows IMI 834 to be successfully heat treated high in the $\alpha+\beta$ phase field. Some reservations were expressed at the out-set that in production the alloy could not be melted and processed to give a reproducible heat treatment window. Now after the production of over 500 tonnes of ingot the reproducibility and consistency of the alloy, and the viability of the heat treatment, are no longer in question.

As has been the recent trend, the product range of IMI 834 has been extended to include sheet, foil and castings. The optimum $\alpha+\beta$ structure of IMI 834 is ideally suited to SPF sheet applications. High strain rate sensitivity values, $m$ values $(0.6-0.8)$, have determined for the alloy at $980^{\circ} \mathrm{C}$. 


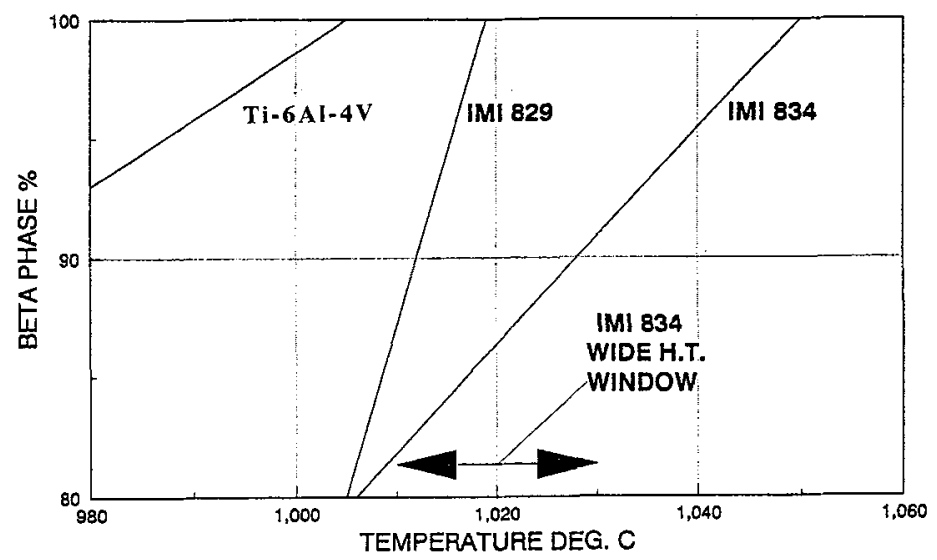

Figure 2. Beta approach curve for IMI 834 in comparison with Ti-6-4 and IMI829.

b) Titanium Aluminides

Given the extensive literature on the alloys, only a few general points will be covered in the following section. The potential of the aluminides can be seen in Table II, which compares them with conventional titanium alloys and superalloys.

Table II Properties of Titanium Aluminides. Titanium - Based Conventional Alloys and Superalloys.

Property $\quad \underline{T i \text { Base }} \underline{\mathrm{Ti}}_{3} \underline{\mathrm{Al}} \quad \underline{\mathrm{TiAl}} \quad \underline{\text { Superalloys }}$

$\begin{array}{lcccr}\text { Density } \mathrm{Mgm}^{-3} & 4.5 & 4.15-4.7 & 3.8 & 8.3 \\ \text { Creep Limit T max }{ }^{\circ} \mathrm{C} & 650 & 700 & 1000 & 1100 \\ \begin{array}{l}\text { Oxidation } \\ \text { (long-term T max }{ }^{\circ} \mathrm{C} \text { ) }\end{array} & 600 & 650 & 900 & 1100 \\ \begin{array}{l}\text { Ductility \% at RT } \\ \text { R }\end{array} & 8-25 & 2-10 & 1-4 & 3-5\end{array}$

While interest still remains in the $\mathrm{Ti}_{3}$ Al-based systems, particularly those based on Super $\alpha_{2}$ ( $\mathrm{Ti}-25 \mathrm{Al}-10 \mathrm{Nb}-3 \mathrm{~V}-1 \mathrm{Mo}$ at $\%$ ), the major emphasis has shifted to exploring the gamma aluminides, where the potential in terms of high temperature performance and density could threaten the supremacy of the superalloys. Though $\mathrm{Ti}_{3} \mathrm{Al}$-based alloys can be processed like conventional titanium alloys, there is a growing view that in their present state of development their advantages over titanium alloys, such as IMI 834 , are insufficiently attractive to justify widespread applications in aerospace projects. The window of opportunity has decreased significantly over the years, as conventional titanium alloys have pushed their temperature ceiling higher and confidence has grown over the potential for success in developing the gamma aluminides. For instance, Figure 3 illustrates the oxidation behaviour of titanium alloys Grade 2 and IMI 834 compared to $\mathrm{Ti}_{3} \mathrm{Al}$ and gamma-based alloys at $900^{\circ} \mathrm{C}{ }^{(5)}$. The potential advantages of the gamma-based systems are apparent, but the graph also illustrates the lack of any benefits accruing to Super $\alpha_{2}$ against IMI 834 .

The engineering limitations of the $\mathrm{Ti}_{3} \mathrm{Al}$-based alloys are widely recognised and in an effort to over-come the alloys' short-comings detailed studies of the Ti-Al-Nb alloy system have led to the discovery of an ordered orthorhombic $\mathrm{Ti}_{2} \mathrm{AlNb}$ phase (O phase) ${ }^{(6)}$. 
Preliminary assessment of alloys based on the $O$ phase plus ordered beta $\left(\beta_{0}\right)$ has shown them to have higher strength to density ratio and better room temperature ductility and fracture toughness than $\mathrm{Ti}_{3} \mathrm{Al}-$ based alloys, with no loss in high temperature properties. The two $\mathrm{Ti}_{2} \mathrm{AlNb}$-based compositions showing particular promise are Ti-24.5Al-23.5 Nb and $\mathrm{Ti}-22 \mathrm{Al}-27 \mathrm{Nb}$ (at\%), whose properties are not only attractive when compared with $\mathrm{Ti}_{3} \mathrm{Al}$-based alloys, but also show specific strength advantages over the superalloy $\mathbb{I N} 718$.

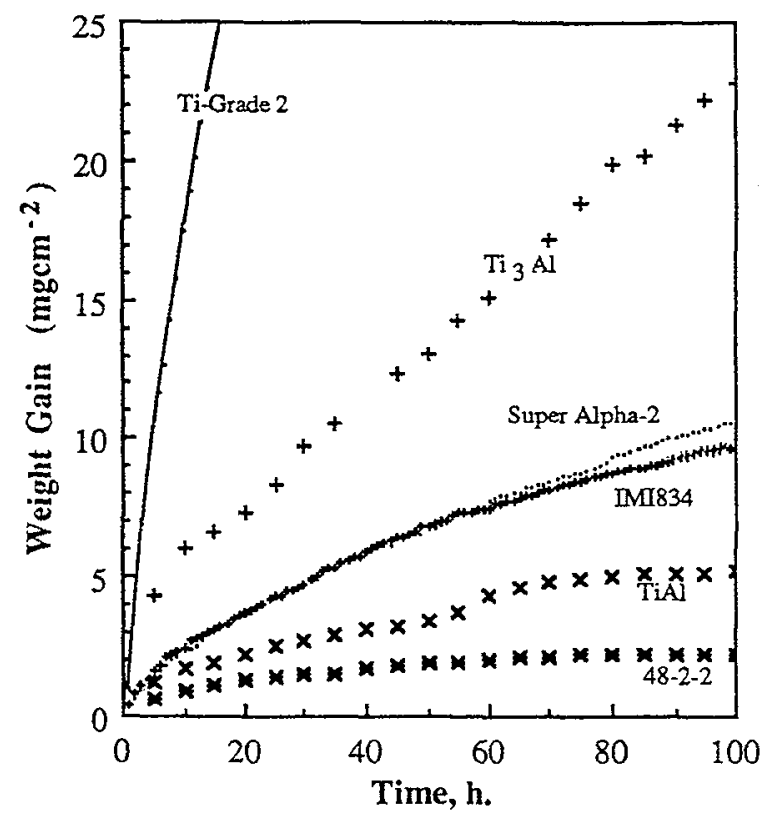

Figure 3 Comparison of Oxidation behaviour at $900^{\circ} \mathrm{C}$.

Within the field of gamma aluminide research, considerable world-wide effort is being directed to the questions of composition and the effect of thermo-mechanical processing on properties, as well as addressing the basic problems of manufacture, which embrace conventional ingot metallurgy, casting and powder production. Although many alloy compositions have been reported in the literature most work has been undertaken on Ti-48Al-2Mn-2 $\mathrm{Nb}$ (at \%).

One of the most interesting developments recently launched in the field of gamma aluminides is the XD ${ }^{\mathrm{TM}}$ process developed by Martin Marietta ${ }^{(7)}$, where the addition of up to 7 volume $\%$ of $\mathrm{TiB}_{2}$, (typically 0.8 volume \% in recent alloys), has resulted in significant improvements in strength, modulus and structural refinement, particularly in cast material.

Realistically the development of intermetallic systems, based on gamma aluminides, must be regarded as long-term, given the problems they present, and the time that will be required to scale-up the development stage and fully validate aerospace components. With a typical gestation period of ten years from the inception to full-scale application of a conventional titanium alloy, a realistic date for significant applications of gamma aluminides is likely to be beyond the turn of the century.

\section{NEW CONVENTIONAL ALLOY DEVELOPMENT}

While the preceding section dealt with high temperature alloys, there have been a number of quite varied alloy developments reported recently, ranging from high strength alloys to non-burning alloys, to alloys for medical applications. Though these programmes do not have a common thread, apart from the fact that they are predominantly based on conventional alloy metallurgy, they do indicate an increasing awareness of the need to solve problems in existing applications, as well as showing how significant efforts are being made to expand the applications for titanium alloys.

Table III lists the alloys in question and indicates the reasons for their development. 
Table III New Conventional Alloy Developments.

\begin{tabular}{lll} 
Alloy & \multicolumn{1}{c}{ Composition (wt\%) } & \multicolumn{1}{c}{ Target } \\
Beta Cez & Ti-5Al-2Sn-4Zr-4Mo-2Cr-1Fe & High strength/medium temperature \\
Beta 21S & Ti-15Mo-2.7Nb-3Al-0.2Si & Cold rolling/MMC's \\
$\begin{array}{l}\text { Protosul 100 } \\
\text { (IMI 367) }\end{array}$ & Ti-6Al-7Nb & Medical/lower toxicity \\
Ti-Zr-Nb & Ti-13Zr-13Nb & Medical/lower toxicity/modulus \\
Ti-Mo-Zr-Al & Ti-15Mo-5Zr-3Al & Medical/lower toxicity/modulus \\
Ti-Mo-Zr-Fe & Ti-12Mo-6Zr-2Fe & Medical/lower toxicity/modulus \\
SP 700 & Ti-4.5Al-3V-2Mo-2Fe & Lower SPF temperature \\
BTT-1 & Ti-Al-Cu & Fire resistant \\
BTT-3 & Ti-Al-Cu & Fire resistant \\
Alloy C & Ti-35V-15Cr & Fire resistant
\end{tabular}

Beta $\mathrm{Cez}{ }^{(8)}$ is aimed at high strength aero-engine applications with a maximum operating temperature of $450^{\circ} \mathrm{C}$. The alloy is a result of a collaborative programme between Snecma, Onera and Cezus and is a potential rival to Ti-17 and Ti-6-2-4-6, having room temperature tensile strength of the order of $1200 \mathrm{MPa}$ and fracture toughness levels of $60 \mathrm{MPa} \mathrm{m}$.

Beta $21 S^{(9)}$ is a cold rollable alloy developed by Timet to address the specific problems of high temperature reactivity that have been encountered in the use of Ti-15-3-3 in the manufacture of MMC's. The alloy has good oxidation and corrosion resistance and is being assessed for potential monolithic applications in the NASP project and as an alternative to 15-3-3 in the Boeing 777.

The next four alloys in Table III, starting with Protosul 100 (IMI 367) ${ }^{(10)}$, have been designed to address specific problems associated with medical applications. Protosul 100 (IMI 367) was developed in Switzerland by Sulzer Bros as an alternative to Ti-6-4. The alloy design set out to overcome the perceived harmful biological effects of vanadium, by its replacement with the non-toxic element niobium. In mechanical property terms the alloy is similar to Ti-6-4. After extensive trials, components, particularly hip joint implants, are now full-scale production.

The other three alloys $(11,12,13)$ listed in Table III are also being developed to address potential problems of biocompatibility by avoidance of $\mathrm{Cr}, \mathrm{Ni}, \mathrm{Sn}$ and $\mathrm{V}$ in their composition, as well as to meet engineering targets with properties compatible with either the modulus, or the yield strength/modulus ratio of bone. This latter parameter is known as the admissible strain and has a value of $0.67 \%$ for human cortical bone (11). The higher values obtained in titanium alloys make them 'more forgiving' in clinic than competitive materials.

The field of alloy development for prostheses is one that has become increasingly active recently following the claims, and counter-claims, of the medical profession of the potential toxic nature of certain elements. As is clear from Figure 4 there is scope for future market exploitation of titanium in the field, but such developments must be undertaken in parallel with sound medical objectives and experiments.

Alloy development aimed at addressing specific manufacturing problems is highlighted by SP 700 (14). This alloy is targetted at reducing production costs by lowering superplastic forming temperatures. By adding beta stabilising elements, the SPF forming temperature of SP 700 has been reduced to $750^{\circ} \mathrm{C}$, compared to a nominal $930^{\circ} \mathrm{C}$ for Ti-6-4. SP 700 continues a development started over 10 years ago (15), where up to $2 \%$ of $\mathrm{Fe}, \mathrm{Cr}$ and $\mathrm{Ni}$ were added to $\mathrm{Ti}-6-4$ to reduce its forming temperature. 


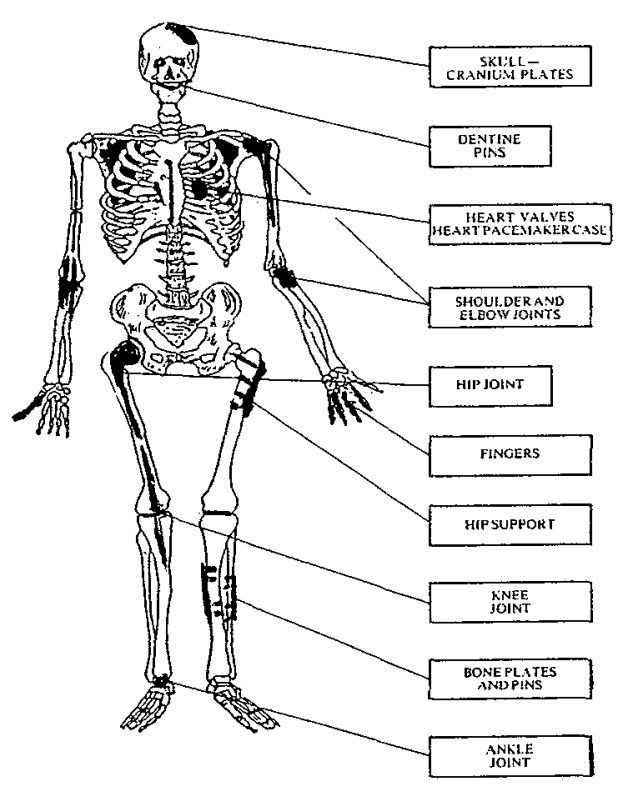

Figure 4 Examples of Titanium alloy medical prostheses.

The final alloys in Table III are aimed at a particular problem in the aero-engine, that of titanium component fires. At the present time the use of titanium alloy components is limited because of fire risks. If the problem could be overcome then more titanium components could be used in engines with the corresponding weight reductions. The alloys BTT-1 and BTT-3 are Russian developments (15), where the fire threshold has been increased to $650^{\circ} \mathrm{C}$ and $>850^{\circ} \mathrm{C}$, respectively. The last alloy in Table III has been developed by Pratt and Whitney, and is a fully beta stabilised one. Under the condition of test the alloy does not burn and has good overall mechanical properties up to about $650^{\circ} \mathrm{C}$.

\section{NEAR NET SHAPE PROCESS DEVELOPMENTS}

a). Casting - The casting industry continues to make developments in terms of quality and size. With greater demands from users for thinner-walled components, studies of the problems of metal flow, porosity, repair, surface finish and mould-surface reactions have resulted in significant improvements in all areas. One somewhat surprising omission from the area is the apparent lack of alloy development specifically aimed at cast components. The industry is still dominated by alloys that were developed for their wrought properties. While clearly the difficult-to-fabricate new materials, particularly those based on gamma aluminide, have used the casting processes, no significant attempts have been made to develop new conventional alloys which address the metallurgical short-comings of the present ones.

b). Superplastic Forming and Diffusion Bonding - The last 10 years have seen superplastic forming and diffusion bonding mature from a development process to full-scale production. All recent aerospace programmes have sought to exploit the cost benefits that accrue from its use in the manufacture of titanium components. The achievments and benefits of the process are well documented. While Ti-6-4 remains the principal alloy of production components, some manufacturing and development studies have been undertaken on the technical/economic benefits of other commercial alloys ( eg Ti-6-2-4-2 and IMI 550 ), together with some limited alloy development, eg SP700.

c). Roll Forming - One of the most striking recent engineering/metallurgical developments in UK has been that at IMI Titanium Ltd in its work on taper rolling (17). The process is extremely versatile. By the use of specially profiled rolls a wide range of shaped plate geometries can be produced in stepped and tapered forms to an extremely high level of dimensional accuracy in combination with a consistent degree of microstructural development. In the first instance near-to-net shape stepped and tapered plates are in production for large aero-engine fan blades. The process is well-established and components are in 
volume production. The technology, originally developed using Ti-6-4, is not alloy-limited and has been extended to other titanium alloys. For example, for some wide-chord hollow fan blade applications where IMI 550 profile rolled plate has been shown to exhibit finer microstructure and superior fatigue properties than the corresponding Ti-6-4 product.

d). Spray-forming and Centrifugal Spray Deposition (CSD) - There are a number of programmes underway world-wide to develop near to net shape processes, particularly for the future generation of materials that are likely to be difficult to process. One of the most interesting of these programmes is the subject of research at the The University of Birmingham, Interdisciplinary Research Centre in Materials for High Performance Applications (18). Spray-forming technology, which has been successfully used on $\mathrm{Al}, \mathrm{Cu}$ and $\mathrm{Fe}$ based alloys, is being developed to produce pre-forms in both conventional titanium alloys and aluminides.

The process under investigation is illustrated in Figure 5. A water-cooled, segmented, copper crucible coupled with induction heating (Cold-Wall Induction Bottom-Pour - CWIBP) provides a source of molten metal for atomisation or spray-forming. Three configurations of the system, shown in Figure 5, allow for the formation of Ti spray deposits in the form of thick sheet, pipe-shaped sprayed on the outside of a drum, or tube-shaped sprayed on the inside of a mould. The first two methods use a pneumatic scanner coupled with a gas atomiser to spray metal. Spray-forming inside a mould is accomplished by centrifugal spray deposition (CSD). CSD consists of a rotating disk which sprays molten metal on the inside of a mould. The mould is programmed to move up and down as the spray deposit builds up on the inside surface. As the process does not involve the use of gas atomisation it eliminates potential problems associated with gas entrapment in the spray deposit and lends itself to operation in vacuum.

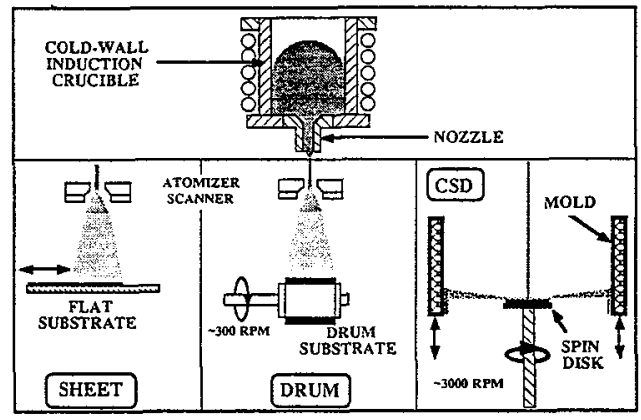

Figure 5. Schematic diagrams of the spray-forming systems.

As will be seen in other papers at this conference although still at an early stage of development, as far as titanium-based alloys are concerned, the preliminary results are encouraging. Not only could the variants of the process offer cost savings in the manufacture of conventional alloy components, but also they may be one of the few routes that could be used to manufacture component from difficult to process alloys, such as gamma aluminides.

\section{METAL MATRIX COMPOSITES}

The development of metal matrix composites straddles the boundaries between alloy, process and product developments. All three technologies interact, but particularly those of process and product development. The driving force behind the technology is higher strength and modulus with lower density and hence reduced component weight. In the ultimate, weight reductions of the order of $75 \%$ have been claimed, when comparing an existing titanium compressor assembly with one designed using composite rings.

Considerable effort has been directed towards the process of production of the titanium matrix with continuous SiC fibre reinforcement and the study of the interactions between the fibre and different alloys. While a number of processes are being evaluated for the production of the titanium matrix, at the present time most of the development thrust is still centred on the use of titanium alloy foil as the starting matrix. Developments have taken place to produce foil in a range of alloys from Ti-6-4 to aluminides. Processes have been developed to manufacture, on a production basis, panels of Ti-6-4, $100 \mu \mathrm{m}$ thick up to $1 \mathrm{~m}$ by $0.5 \mathrm{~m}$ in area. Other alloys, such as IMI 834 , Ti 1100 and super $\alpha_{2}$, have been successfully 
produced on a development scale, while cold rollable alloys, such as Ti-15-3-3 and Beta 21S, are readily available in foil. Typical tensile and Young's modulus values of a number of MMC, using foil and BP Composite's Sigma SiC fibre, are shown in Figure 6.

A particularly exciting development in the UK is being undertaken at DRA Farnborough (19), using a physical vapour deposition process to coat $\mathrm{SiC}$ fibres with titanium alloys. Technically, the process has many attractions. In the first instance, there is no restriction on alloy matrix composition, matrix thickness around the fibre can be varied without difficulty and on consolidation, the problems often encountered in the foil route, in terms of spacing and fibre movement, are eliminated. Consolidated, coated SiC fibre MMC with $80 \mathrm{vol} \%$ fibre have been produced. The process which, until recently was only operating on a small scale, is being scaled-up to produce continuous lengths of coated fibre.

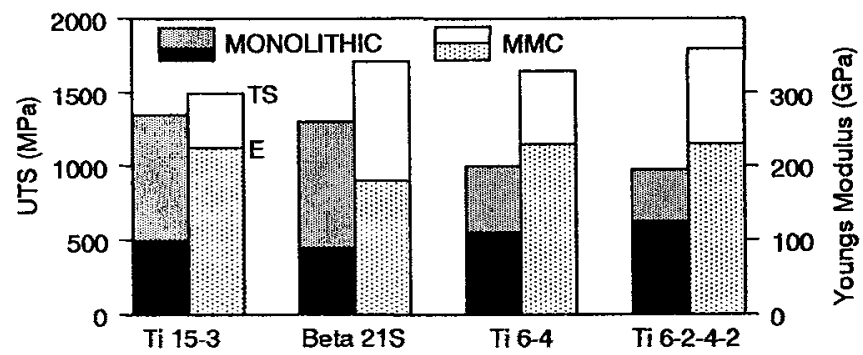

Figure 6 Comparison of Tensile and Young's Modulus of SiC reinforced MMC's with Monolithic Materials.

\section{CONCLUSIONS}

The paper has had to be restricted in its content and there are a number of topics, that it has been necessary to omit. However, the message to the alloy/process developer should be clear, that there are still many opportunities to develop new alloys and processes and establish new markets, while at same time extending opportunities for existing alloys.

\section{REFERENCES}

1.BLENKINSOP P. A. Titanium Science and Technology, DGM (1985), 2322.

2.PHELPS H. R. To be published in the Proceedings of the 7th World Titanium Conference, San Diego, (1992).

3.DAUBLER M. A., et al. Titanium 1990 Products and Applications, Dayton TDA (1990),78.

4.O'CONNELL T. E. and BANIA P.J., ibid. 794-803.

5.JOHNSON T.J. To be published in the Proceedings of the 7th World Titanium Conference, San Diego, (1992).

6.ROWE R. G. Microstructure/property Relationships in Ti Aluminides, TMS, (1991), 387.

7.WHEELER D. A. et al. To be published in the Proceedings of the 7th World Titanium Conference, San Diego, (1992).

8.COMBRES Y. et al., ibid.

9.BANIA P. J. and PARRIS W. M., ibid.

10.SEMLITSCH M. Designing with Titanium, London, Institute of Metals, (1986), 292.

11.STEINEMANN S., et al. To be published in Proceedings of the 7th World Titanium Conference, San Diego (1992).

12.WANG K. et al., ibid.

13.KOVACS P. et al., ibid.

14.ISHIKAWA M., et al., ibid.

15.WERT J. and PATON N. E. Metallurical Transactions, (1983), 14A, 2335.

16.TETYUKHIN V. V. Titanium 1990 Products and Applications, Dayton,TDA, (1990), 56.

17.KEARNS M.W. Private communication with author, IMI Ti Ltd, March (1993).

18.JACOBS M. H., et al. To be published in the Proceedings of Powder Metallurgy in Aerospace, Defense and Demanding Applications, San Diego, (1993).

19.PARTRIDGE P. G., and C M WARD-CLOSE C. M. To be published in the Proceedings of the 7th World Titanium Conference, San Diego, (1992). 